\title{
Road intersections ranking for road safety improvement: Comparative analysis of multi-criteria decision making methods
}

\author{
Gianfranco Fancello*, Michele Carta, Paolo Fadda \\ D.I.C.A.AR, Department of Civil and Environmental Engineering and Architecture, University of Cagliari, 09123 Cagliari, Italy
}

\section{A R T I C L E I N F O}

\section{Keywords:}

Road safety

Multi-criteria analysis

Ranking

Road intersection

\begin{abstract}
A B S T R A C T
The aim of this paper is to propose a methodology for identifying the most critical road sections in urban networks in terms of road safety. This approach is useful for the managers of the road network when they need to allocate limited financial resources to several critical sections. Since the resources are not always sufficient to solve all road safety issues, they require a methodology that is able to rank the critical sections. Road safety depends on the interaction of several factors so this methodology has to be based on a multicriteria approach. In earlier articles, the authors of this paper first adopted Electre III and later Concordance Analysis as multicriteria methods for ranking critical points in an urban road network. Both methods have some critical elements, associated with threshold choice (Electre III) and ranking procedure (Concordance Analysis). In order to improve the methodology, the authors have selected two further multicriteria methods (Vikor and Topsis), for comparison with the Concordance Analysis and for evaluating which performed best. In order to identify critical sections in a road network, a suitable set of indicators is defined, taking into account geometric and traffic volume criteria. The multicriteria methods are applied to a real case for ranking, from the worst safety conditions to the best, the most critical road intersections within the urban road network, on the basis of eight criteria. The results of all three methods considered are compared and a sensitivity analysis is performed to test the stability of the results. The results show that the Topsis method performs best in determining a complete ranking of the critical road sections, overcoming some negative aspects associated with the other methods.
\end{abstract}

\section{Introduction}

One of the most important tasks of urban road network managers is to choose how to allocate limited financial resources for solving road safety problems. This issue presents some challenges as the priority is often defined in different ways, depending on local conditions. For this reason, decision support systems are becoming key tool for supporting managers to make the best choice for the optimal allocation of financial resources. Most decision support systems rely on multicriteria analysis, that, as is well known, adopt different methods. Some are defined with respect to "Alpha" problems (identify only the best choice), others to "Beta" problems (identify clusters of several options), others to "Gamma" problems (build a ranking of several options). Clearly the choice of best method depends on the problem to be solved, the variables, the subjects involved, the objectives, etc. The aim of this paper is to propose a decision support system based on multicriteria approach for identifying the most critical road intersections in urban networks in terms of road safety. This methodology compares different road intersections in order to determine the most hazardous on the basis of a set of safety criteria. A hierarchy of hazardous intersections is built from the worst safety performance to the best. This methodology provides support to urban road network Managers for ranking safety interventions. By focusing on hazardous junctions, resources can be allocated to address critical safety issues by developing and implementing countermeasures to reduce accident frequency and severity. A methodology able to support decision-making process is required due the large number of data involved. Over the last years several studies have analysed the ranking of different options, based on the total number of accidents that have occurred: these accidents are measured either using statistical data, or by means of forecasting models (Miranda-Moreno et al., 2005; Huang et al., 2010; Fancello et al., 2017). Accident data may not always be available for the whole network or not represented in a suitable way. In order to overcome the unavailability of accident data and to also consider road intersections without accidents (but potentially hazardous) in road safety analysis, the Manager needs to base the manage of safety on additional parameters on which he can build a hierarchy based on safety conditions. Accordingly, it can be useful to define a methodology based on different road safety

\footnotetext{
* Corresponding author.

E-mail address: fancello@unica.it (G. Fancello).
} 
parameters rather than on the number of accidents. Agarwal in (Agarwal et al., 2013) presents a methodology for ranking road safety hazardous locations. Analytical hierarchy process (AHP) is used to determine the weight of the different identified safety factors when road accident data is not available. In (Keymanesh et al., 2017) also is defined a methodology to identify and prioritize the accident prone points (black spots) without no use of accident data. Both work are based on road safety audit technique. In order to support decision making of the City Manager, it's important to propose a methodology based on road safety audit because it involves parameters on which he can plan material interventions to improve safe driving conditions, like geometric and traffic flow characterics. This analysis includes the following evaluation criteria related to road safety audit: access sight distance, traffic volume, road surface maintenance and number of conflict points. There are many known methods for performing multicriteria decision analyses and for ranking critical road junctions or sections. In other earlier works, the authors first adopted Electre III (Fancello et al., 2014) and later concordance analysis (Fancello et al., 2015), but both methods had some critical elements:

- Electre III, though suitable for ranking several options, requires three thresholds (indifference, preference and veto thresholds) to be defined "a priori" by the user, and thus is not useful for ranking purposes involving the allocation of public financial resources;

- Concordance Analysis is a typical method of "alpha" problems, that identifies the best choice but is not able to create a ranking. Then the Concordance Analysis algorithm has been performed iteratively by removing from each iteration the chosen alternative from the set of decision alternatives and then repeating the analysis on the remaining ones. The final ranking is given by the sequence of alternatives removed from the set. The absence of best choice in some iteraction sets and the difficulty in correctly determining the distance from the best choice to the other options are the critical aspects of concordance analysis.

Here the authors intend to overcome these critical aspects by introducing two multicriteria methods frequently used in the international scientific literature which allow to rank a set of alternatives: Vikor and Topsis. The aim is to compare these two methods with concordance analysis (Electre III has not been considered), and then to choose the best performer to be introduced into the decision support system for city managers. Clearly the method chosen needs to be able both to create a ranking of several options and to be impartial in the evaluation of several options.

The three multi-criteria methods have been applied to a real case. We analysed safety conditions of a set of intersections in an urban road network in a small town (Villacidro, Sardinia) in Italy. In order to rank hazardous intersections, the authors have determined several safety criteria by means of direct surveys and traffic counts. The results obtained with the three methods are comparable as they provide a hierarchy of alternatives on the basis of pairwise comparison according to several criteria. Each methodology adopts its own algorithm and the results are not always consistent with one another. The different hierarchies of hazardous sections are shown and compared in this study. In paragraph 2, the state of art on multicriteria decision making methods is described and the algorithm of the three methods examined are presented. In paragraph 3 is presented a brief state of the art of key performance indicators for measuring road safety performance and the set of key indicators used in this study. Paragraph 4 describes the real case application of these methodologies. The sensitivity analysis is discussed in Paragraph 5 and Paragraph 6 presents the conclusions.

\section{State of the art on multi-criteria methodologies}

Decision making processes in complex systems are based on multiple decision makers and criteria. Decision makers must take into account conflicting points of view and choose one or more alternatives that perform best on all conflicting criteria (Belton et al., 2002). Different multicriteria analysis approaches are presented in the scientific literature for solving different kinds of issues. In multicriteria decision support methodologies three main types of problems can be identified: choice issue "alpha problematique", sorting issue "beta problematique" and ranking issue "gamma problematique" (Figueira et al., 2005). In the first case, the desired result is to select the subset of best alternatives whereas in the second, the decision alternatives are sorted into a predefined set of ordered categories. In the last case all the alternatives are ordered from the best to the worst (Olteanu et al., 2011). In this work the authors present different methodologies for ranking hazardous road sections and establishing priority for future road safety actions (Zopounidis et al., 2002). In order to rank all considered sections a methodology suitable for "gamma problematique" is required. The following methods have been adopted here for performing the analysis: Vikor (as described by Opricovic (1998), Topsis (as described in Yoon et al., 1995) and Concordance Analysis (as described in (Giuliano, 1985). These methods are used for different applications: Vikor in education centres in universities (Wu et al., 2011), yarn production process (Moghassem (2013), customer satisfaction in mobile services (Kang et al., 2014), material selection problems (Jahan, 2013), ergonomically designed products (Mohanty, 2014); Topsis in road alignment variants (Gardziejczyk, 2014), enterprises comparison (Deng et al., 2000), road safety performance evaluation (Bao, 2012); Concordance Analysis in transportation investment planning (Giuliano, 1985), road safety performance evaluation (Fancello et al., 2015). The Vikor and Topsis methods rank alternatives according to different objective functions. The general idea of these methods is based on the measure of closeness to the ideal solution, according to the set of criteria. The concordance analysis method is derived from Electre I and uses the outranking relations based on both concordance and discordance analysis. This technique solves the " $\alpha$-problematique" whose aim is to identify the set of best alternatives. In this work we have adapted this method in order to compare the results with other related multicriteria methods based on a ranking order. The algorithms of these three methods are shown in the following paragraphs.

\subsection{Vikor}

The Vikor (from Serbian: VIseKriterijumska Optimizacija I Kompromisno Resenje) method was developed for multi-criteria optimization of complex systems. This method determines the compromise ranking-list of a set of alternatives $A_{1}, A_{2}, \ldots, A_{J}$, in the presence of $n$ possibly also conflicting criteria. Vikor introduces the multi-criteria ranking index based on the measure of closeness to the ideal solution (Opricovic, 1998). The compromise ranking algorithm Vikor has the following steps:

Step I: determine the best $f_{i}{ }^{*}$ and the worst $f_{i}^{-}$values of all criterion functions, $i=1,2, \ldots, n$. If the $i$-th objective function represents a benefit then $\mathrm{f}_{\mathrm{i}}^{*}=\max \left(\mathrm{f}_{\mathrm{ij}}\right)$ and $\mathrm{f}_{\mathrm{i}}^{-}=\min \left(\mathrm{f}_{\mathrm{ij}}\right)$ while if the $\mathrm{i}$-th function represents a cost $f_{i} *=\min \left(f_{i j}\right)$ and $f_{i}^{-}=\max \left(f_{i j}\right)$.

Step II: compute the values $S_{j}$ and $R_{j}, j=1,2, \ldots, J$, by the relations

$S_{j}=\sum_{i=1}^{n} w_{i}\left(f_{i}^{*}-f_{i j}\right) /\left(f_{i}^{*}-f_{i}^{-}\right)$.

$R_{j}=\max _{i}\left[w_{i}\left(f_{i}^{*}-f_{i j}\right) /\left(f_{i}^{*}-f_{i}^{-}\right)\right]$.

where $\mathrm{w}_{\mathrm{i}}$ are the weights of criteria, expressing the decision makers's preference as the relative importance of the criteria, $\mathrm{J}$ is the number of alternatives.

Step III: compute the values $Q_{j}, j=1,2, \ldots, J$, where, by the relation

$Q_{j}=v\left(S_{j}-S^{*}\right) /\left(S^{-}-S^{*}\right)+(1-v)\left(R_{j}-R^{*}\right)$.

Where: 
$S^{*}=\min _{j} S_{j}, S^{-}=\max _{j} S_{j}, R^{*}=\min _{j} R_{j}, R^{-}=\max _{j} R_{j}$ and $v$ is introduced as a weight for the strategy of maximum group utility.

Step IV: rank the alternatives, sorting by the values $S, R$ and $Q$, in decreasing order. The results are three ranking lists. Propose as a compromise solution the alternative $\left(\mathrm{A}^{(1)}\right)$ which is the best ranked by the measure $\mathrm{Q}$ (minimum) if the following two conditions are satisfied:

Condition 1: Acceptable advantage.

$Q\left(A^{(2)}\right)-Q\left(A^{(1)}\right) \geq D Q$.

where $A^{(2)}$ is the alternative with second position in the ranking list by $\mathrm{Q}$ and $\mathrm{DQ}=1 /(\mathrm{J}-1)$

Condition 2: Acceptable stability in decision making.

Alternative $\mathrm{A}^{(1)}$ must also be the best ranked by $\mathrm{S}$ or/and $\mathrm{R}$.

If one of the conditions is not satisfied, then a set of compromise solutions is proposed, which consists of:

1 alternatives $\mathrm{A}^{(1)}$ and $\mathrm{A}^{(2)}$ if only condition $\mathrm{C} 2$ is not satisfied or 2 alternatives $A^{(1)}, A^{(2)}, \ldots, A^{(M)}$ if condition $C 1$ is not satisfied; and $A^{(M)}$ is determined by the relation $Q\left(A^{(M)}\right)-Q\left(A^{(1)}\right)$ for maximum $n$ (the positions of these alternatives are in closeness).

\subsection{Topsis}

The Topsis (Technique for Order Preference by Similarity to an Ideal Solution) method is presented in Chen and Hwang (Chen et al., 1992), with reference to Hwang and Yoon (Hwang et al., 1981). The basic idea of this method is that the best compromise alternative should have the shortest distance from the ideal solution and the farthest distance from the negative-ideal solution. The Topsis procedure consists of the following seven steps:

Step I: calculate the decision matrix, where the $\mathrm{j}$ rows are the various alternatives denoted as $A_{1}, A_{2}, \ldots, A_{j}$, the $n$ columns are the criteria function and a single element $f_{i j}$ is the value of the criterion $i=1,2, \ldots$, $n$ for the alternative $A_{j}$.

Step II: calculate the normalized decision matrix. Each normalized value $r_{i j}$ is calculated as

$r_{i j}=f_{i j} / \sum_{j=1}^{J} f_{i j}^{2}, j=1, \ldots, J, i=1, \ldots, n$.

Where $f_{i j}$ is the value of the objective function $i$ for the alternative $A_{j}$.

Step III: calculate the weighted normalized decision matrix. The weighted normalized value $\mathrm{v}_{\mathrm{ij}}$ is calculated as:

$v_{i j}=w_{i} w i r_{i j}, j=1, \ldots, J, i=1, \ldots, n$.

where wi is the weight of the $\mathrm{i}$-th objective function and $\sum_{i=1}^{n} w_{i}=1$.

Step IV: determine the ideal solution:

$A^{*}=\left\{v_{1}^{*}, \ldots \ldots, v_{n}^{*}\right\}$,

$=\left\{\left(\max _{j} v_{i j} \mid i \in I^{*}\right),\left(\min _{j} v_{i j} \mid i \in I^{-}\right)\right\}$.

and negative-ideal solution:

$A^{-}=\left\{v_{1}^{-}, \ldots \ldots, v_{n}^{*}\right\}$,

$=\left\{\left(\min _{j} v_{i j} \mid i \in I^{*}\right),\left(\max _{j} v_{i j} \mid i \in I^{-}\right)\right\}$.

where $\mathrm{I}^{*}$ is a set of benefit criteria, and $\mathrm{I}^{-}$is a set of cost criteria.

Step V: calculate the separation measures, using the n-dimensional Euclidean distance. The separation of each alternative from the ideal solution is given as

$D_{j}^{*}=\sqrt{\sum_{i=i}^{n}\left(v_{i j}-v_{i}^{*}\right)^{2}}, j=1, \ldots, J$.

Similarly, the separation from the negative ideal solution is given as

$D_{j}^{-}=\sqrt{\sum_{i=i}^{n}\left(v_{i j}-v_{i}^{-}\right)^{2}}, j=1, \ldots, J$.
Step VI: calculate the relative closeness to the ideal solution. The relative closeness of the alternative $A_{j}$ with respect to $A *$ is defined as

$C_{j}^{*}=D_{j}^{-} /\left(D_{j}^{*}+D_{j}^{-}\right), j=1, \ldots . J$.

Step VII: rank the preference order according to value of $\mathrm{C}_{\mathrm{j}}^{*}$. The best alternative has the lowest value of $\mathrm{C}_{\mathrm{j}}{ }^{*}$.

\subsection{Concordance analysis}

The "Concordance Analysis", as described by Giuliano in (Giuliano, 1985), is derived from Electre I and uses the outranking relations based on both concordance and discordance analysis. This techniques solves the " $\alpha$-problematique" whose aim is to identify the best one or a set of good ones alternative. In this work we have adapted this method in order to compare the results of this method with other related multicriteria method based on a ranking order. This model consists of the following steps:

Step I: specification of decision matrix $\mathrm{M}_{\mathrm{ij}}, 1 \leq \mathrm{i} \leq \mathrm{k}, 1 \leq \mathrm{j} \leq \mathrm{h}$. The decision matrix is a two dimensional array $\mathrm{k} \mathrm{xh}$, where $\mathrm{k}$ rows are the objective functions $g_{k}$, the $h$ columns are the alternatives $a_{h}$ and the element $\mathrm{p}_{\mathrm{ij}}$ is the value of the objective functions $g_{\mathrm{k}}$ for the alternative $\mathrm{a}_{\mathrm{h}}$.

Step II: assignment of weights $\mathrm{w}_{\mathrm{k}}$ to the criteria $\mathrm{g}_{\mathrm{k}}$. In this phase a hierarchy has been defined between the objective functions themselves. The weighting schemes are based on the recommendations put forward by the decision maker.

Step III: concordance and discordance matrices. With the concordance - discordance method, two matrices need to be created by comparing the alternatives to define the system of final preferences.

The elements $\mathrm{c}_{\mathrm{ij}}$ of the concordance matrix are defined as:

$c_{i j}=\sum_{k \in C_{i j}}\left(w_{k}\right)$

where:

$C_{i j}=k: p_{k i} \geq p_{k j}$

The elements $d_{i j}$ of the discordance matrix are defined as:

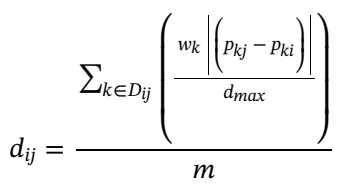

where:

$D_{i j}=k: p_{k i} \leq p_{k j}, \forall i \neq j$

$d_{\max }=\max \left\{w_{i}\left|p_{k i}-p_{k i}\right|\right\}$

$m=\max _{i j}$, number of elements in $\mathrm{D}_{\mathrm{ij}}$

Step IV: concordance index and discordance index. The concordance index $\mathrm{Ic}_{\mathrm{i}}$ symbolizes the total satisfaction of the decision-maker choosing the $a_{i}$ alternative instead of the $a_{j}$.

$I c_{i}=\sum_{j} c_{i j}-\sum_{j} c_{j i}$

The discordance index $\mathrm{Id}_{\mathrm{i}}$ reflects the regret of the decision-maker in choosing the $\mathrm{a}_{\mathrm{i}}$ alternative instead of the aj:

$I d_{i}=\sum_{j} d_{i j}-\sum_{j} d_{j i}$

Step V: ranking of the alternatives. The alternatives are ordered by increasing the concordance index and decreasing the discordance index to obtain two lists. The alternatives choice have a positive $\mathrm{Ic}_{\mathrm{i}}$ and negative $\mathrm{Id}_{\mathrm{i}}$. In cases where an alternative has a negative concordance index and/or positive discordance index, this not represents the best 
compromise solution and the last position in the ranking has been given. The hierarchy of this alternatives is built according to the difference of the value between the concordance and discordance index. The alternatives with higher difference values are preferred over the others.

\section{Selection of criteria}

In this paper the authors have defined a suitable set of indicators on the basis of the results of others earlier works (Fancello 2014, 2015) and of the scientific literature on road safety issues. A literature analysis was performed to determine which indicators may be relevant in a road safety context. Safety is not exclusively determined by road characteristics but it also depends on the interactions between several elements and can be defined using the elementary triangle of road safety: road, human and vehicle (Sarrazin et al., 2011; Colonna, 2002). A schematic overview of road safety indicators is also presented by (Hermans et al., 2008) which provides a construction process of composite road safety performance considering the following: alcohol and drugs, protective system, vehicle, speed, daytime running lights, infrastructure and trauma care (Janssen, 1991). proposes a set of nine indicators specific for safety at junctions including average daily motorvehicle volume, accidents involving casualties per junction, casualities and fatalities per accident. As already said, this methodology supports local Administration in determining the ranking of black spot. Once the most unsafe black spot have been indentified, decision maker will be able to plan interventions to improve road safety. For this reason this methodology is based on only evaluation criteria related to parameters on which the administrator/decision maker can plan material interventions. Furthermore the criteria have to be based on data directly available to the Administration or derivable from available data. This methodology is not based on elements related to safety but not under the competence of the Administration (as roads, junctions, road lights, etc.) and it is not based on data that may be unavailable (as operational speed or with long term effects like prevention and awareness campaign). Each criterion defined in the following is related to specific areas that it is within the authority of local government of the road network. It is important to define the area of analysis ("A") of each road intersection in order to calculate the safety criteria. "A" is the area where the interference among different flows occurs at the intersection (vehicle and pedestrian manoeuvres, parking, bus stop, ...). If it is not possible to perform specific analyses to identify the boundaries of this area, the authors suggest setting the distance at $75 \mathrm{~m}$ upstream from the stop line of each arm, as defined in HCM manual (HCM, 2000) for measuring parameters related to delay at intersections.

Each criteria is represented by a scalar value and by a preference direction: higher values of the criterion are preferred to lower ones if the preference direction is ascending; on the contrary, lower values of the criterion are preferred to higher ones if the preference direction is descending. The key indicators considered are described in the following:

- $\mathrm{I}_{1}$, Sight distance from access [m]. The driver approaching an intersection should have an unobstructed view of the entire intersection and an adequate view of the intersecting road to permit control of the vehicle to avoid a collision. The value of this indicator increases with sight distance from each approach: absent (1), poor (2), fair (3), good (4). This criterion is calculated by on-site measurements. To determine the road sections with worst safety condition, the objective is to minimize the criterion.

- $\mathrm{I}_{2}$, road signs and markings. This indicator increases as safety conditions improve: absent (1), poor (2), fair (3), good (4). This criterion is calculated by visual inspection. The objective is to minimize the criterion.

- $\mathrm{I}_{3}$, intersection lighting. The value of the level of illumination indicator increases as lighting conditions improve: absent (1), poor
(2), fair (3), good (4). This criterion is calculated by visual inspections of site conditions. The objective is to minimize the criterion.

- $\mathrm{I}_{4}$, road surface maintenance. The presence of rutting, ponding, cracking, potholes, etc. increases the risk of accidents due to reduced vehicle control. The road surface indicator increases as surface conditions improve: poor (1), low (2), fair (3), good (4). The objective is to minimize the criterion. This criterion is calculated by visual inspection of site conditions. The objective is to minimize the criterion.

- $\mathrm{I}_{5}$, density of traffic conflict points. This indicator is calculated from the ratio of traffic conflict points between vehicles at intersection to intersection area. The objective is to maximize the criterion. This criterion is calculated by analysing the trajectories generated by the traffic flows. The objective is to maximize the criterion.

- $\mathrm{I}_{6}$ number of vehicles entering the intersection area. This indicator is defined as the sum of traffic flows entering the intersection (in the analysis area "A") during the peak hour from all approaches. This criterion is determined by means of traffic counts at the intersection. The objective is to maximize the criterion.

- $\mathrm{I}_{7} \%$ heavy vehicles. This indicator is defined as the percentage of heavy vehicles entering the intersection analysis area "A". This criterion is determined by means of traffic counts at the intersection. The objective is to maximize the criterion.

- $\mathrm{I}_{8}$, pedestrian flow. This indicator is defined as the sum of pedestrian flows entering the intersection analysis area "A" during peak hour from all approaches. This criterion is determined by manual counts at the intersection. The objective is to maximize the criterion.

\section{Case study}

The three multi-criteria methods Topsis, Vikor and Concordance Analysis, as described in the paragraph 2, are applied to a real case to support the urban road network managers of the city of Villacidro in Italy in transportation planning issue. The aim is to build a hierarchy of the most unsafe intersections in the urban network, in order to realise a plan of priority interventions to improve road safety. A previous Strategic Plan of Villacidro city identified a subset of six intersections among all, as priorities for Public Administration policy. The methodology presented in this study is applied to build a hierarchy of these six intersections ranked from the worst safety conditions to the best, according to the eight criteria $\left(\mathrm{I}_{1}, \ldots, \mathrm{I}_{8}\right)$ described above. The values of the criteria are determined for each junction in the set. Fig. 1 shows the road network of Villacidro where the red points are the junctions selected for multi-criteria assessments. The decision matrix in Table 1 shows the values for each criterion.

The relative importance among the criteria is established by the decision-maker with scientific support given by the authors. The decision-maker has assigned to each criterion a numeric value that represents the relative importance in improving safety conditions, through appropriate actions within his authority. The vector of weights is defined by:

$w=\left(w_{1}, w_{2}, w_{3}, w_{4}, w_{5}, w_{6}, w_{7}, w_{8}\right)$

where $\mathrm{w}_{1}, \ldots, \mathrm{w}_{8}$ are real numbers from 0 to 1 inclusive, which satisfy the condition:

$\sum_{i=1}^{8} w_{i}=1$

The most important criterion, according to the preferences of the decision-maker is the adequacy of the sight distance $\left(\mathrm{w}_{1}\right)$, with $22.5 \%$ of the total weight (unitary weight). The condition of the road surface $\left(\mathrm{w}_{4}\right)$ and the traffic flow $\left(\mathrm{w}_{6}\right)$ both take a weight equal to $17.5 \%$. A weight of $12.5 \%$ is assigned to intersection lighting $\left(\mathrm{w}_{3}\right)$ and density of conflict points $\left(\mathrm{w}_{5}\right)$. The decision-maker assigns a lower weight to road signs and markings conditions $\left(\mathrm{w}_{2}\right)$ and pedestrian flow $\left(\mathrm{w}_{8}\right)$, equal to 


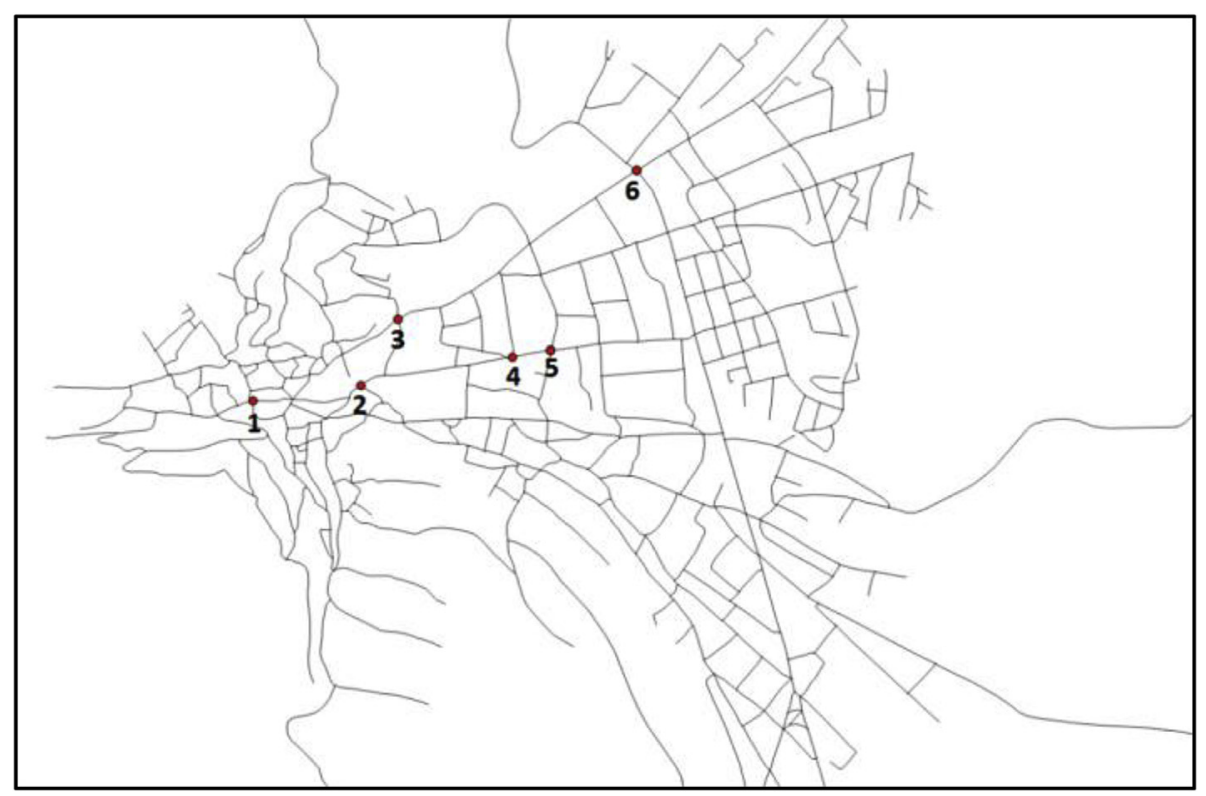

Fig. 1. Villacidro road network.

Table 1

Decision matrix.

\begin{tabular}{lllllllll}
\hline intersection $/$ criterion & $\mathrm{I}_{1}$ & $\mathrm{I}_{2}$ & $\mathrm{I}_{3}$ & $\mathrm{I}_{4}$ & $\mathrm{I}_{5}$ & $\mathrm{I}_{6}$ & $\mathrm{I}_{7}$ & $\mathrm{I}_{8}$ \\
\hline $\begin{array}{l}\text { 1. A1. Via Scuole - via Don Bosco - via } \\
\quad\end{array}$ & 2 & 3 & 2 & 3 & $13 / 224$ & 507 & 4.2 & 36 \\
$\quad$ G.M. Angioi & 2 & 1 & 3 & 3 & $4 / 188$ & 322 & 4.5 & 46 \\
2. A2. Piazza Lavatoio & 3 & 3 & 3 & 3 & $22 / 846$ & 635 & 4.2 & 50 \\
3. A3. Piazza Rondò & 2 & 2 & 2 & 2 & $4 / 109$ & 530 & 4.1 & 20 \\
4. A4. via Repubblica - via Azzini & 4 & 3 & 3 & 4 & $9 / 396$ & 769 & 4 & 24 \\
$\begin{array}{l}\text { 5. A5. via Regione Sarda - via } \\
\quad \text { Repubblica }\end{array}$ & 4 & 4 & 3 & 4 & $8 / 457$ & 991 & 3.9 & 32 \\
6. A6. via Parrocchia - via Nazionale & 4 & & & & & & &
\end{tabular}

Table 2

Vikor method, values of $S_{j}, R_{j}$ and $Q_{j}$.

\begin{tabular}{lllllll}
\hline & $\mathrm{A}_{1}$ & $\mathrm{~A}_{2}$ & $\mathrm{~A}_{3}$ & $\mathrm{~A}_{4}$ & $\mathrm{~A}_{5}$ & $\mathrm{~A}_{6}$ \\
\hline $\mathrm{S}_{\mathrm{j}}$ & 0.31 & 0.51 & 0.58 & 0.30 & 0.83 & 0.80 \\
$\mathrm{R}_{\mathrm{j}}$ & 0.13 & 0.18 & 0.13 & 0.12 & 0.23 & 0.23 \\
$\mathrm{Q}_{\mathrm{j}}$ & 0.04 & 0.46 & 0.28 & 0.00 & 1.00 & 0.97 \\
\hline
\end{tabular}

Table 3

Vikor method, final ranking.

\begin{tabular}{ll}
\hline 1 st & $\mathrm{A}_{4}$ \\
\hline $2^{\text {nd }}$ & $\mathrm{A}_{1}$ \\
$3^{\text {rd }}$ & $\mathrm{A}_{3}$ \\
$4^{\text {th }}$ & $\mathrm{A}_{2}$ \\
\hline
\end{tabular}

Table 4

Topsis method, closeness of the ideal alternative.

\begin{tabular}{lllllll}
\hline & $\mathrm{A}_{1}$ & $\mathrm{~A}_{2}$ & $\mathrm{~A}_{3}$ & $\mathrm{~A}_{4}$ & $\mathrm{~A}_{5}$ & $\mathrm{~A}_{6}$ \\
\hline $\mathrm{S}^{-} /\left(\mathrm{S}_{\mathrm{i}}{ }^{*}+\mathrm{S}_{\mathrm{i}}^{-}\right)$ & 0.66 & 0.46 & 0.43 & 0.62 & 0.22 & 0.26 \\
\hline
\end{tabular}

$7.5 \%$ of the total weight and $2.5 \%$ to the criterion with the lowest weight, heavy vehicles $\left(\mathrm{w}_{7}\right)$. The vector of weight, defined on the basis of the preferences of the decision maker is:

$w_{1}=(0.225,0.075,0.125,0.175,0.125,0.175,0.025,0.075)$

With the Vikor method the final ranking is built by comparing the
Table 5

Topsis method, final ranking.

\begin{tabular}{ll}
\hline 1 st & $\mathrm{A}_{1}$ \\
\hline $2^{\text {nd }}$ & $\mathrm{A}_{4}$ \\
$3^{\text {rd }}$ & $\mathrm{A}_{2}$ \\
$4^{\text {th }}$ & $\mathrm{A}_{3}$ \\
$5^{\text {th }}$ & $\mathrm{A}_{6}$ \\
$6^{\text {th }}$ & $\mathrm{A}_{5}$ \\
\hline
\end{tabular}

Table 6

Concordance method, concordance and discordance indexes.

\begin{tabular}{llllll}
\hline $\mathrm{Ic}_{1}$ & $\mathrm{Ic}_{2}$ & $\mathrm{Ic}_{3}$ & $\mathrm{Ic}_{4}$ & $\mathrm{Ic}_{5}$ & $\mathrm{Ic}_{6}$ \\
\hline 1.50 & 0.08 & 0.35 & 2.08 & -1.83 & -2.18 \\
\hline $\mathrm{Id}_{1}$ & $\mathrm{Id}_{2}$ & $\mathrm{Id}_{3}$ & $\mathrm{Id}_{4}$ & $\mathrm{Id}_{5}$ & $\mathrm{Id}_{6}$ \\
\hline 0.61 & 0.54 & 0.31 & -0.23 & -0.24 & -1.00 \\
\hline
\end{tabular}

Table 7

Final ranking.

\begin{tabular}{llll}
\hline Ranking & Vikor & Topsis & Concordance Analysis \\
\hline $1^{\text {st }}$ & $\mathrm{A}_{4}$ & $\mathrm{~A}_{1}$ & $\mathrm{~A}_{4}$ \\
$2^{\text {nd }}$ & $\mathrm{A}_{1}$ & $\mathrm{~A}_{4}$ & \\
$3^{\text {rd }}$ & $\mathrm{A}_{3}$ & $\mathrm{~A}_{2}$ & \\
$4^{\text {th }}$ & $\mathrm{A}_{2}$ & $\mathrm{~A}_{3}$ & \\
$5^{\text {th }}$ & & $\mathrm{A}_{6}$ & \\
$6^{\text {th }}$ & & $\mathrm{A}_{5}$ & \\
\hline
\end{tabular}

measure of closeness to the ideal alternative. Table 2 shows the values of $S_{j}, R_{j}$ and $Q_{j}$ calculated by the algorithm and the final ranking is given in Table 3 . On the basis of the set of weights provided by the decision maker the Vikor method creates a ranking where the first place is occupied by the intersection " $\mathrm{A}_{2}$ " (4th) with the worst safety performance.

According to the algorithm the condition of "Acceptable advantage" (5) is not satisfy and the method provide a partial ranking of only four intersections.

The Topsis method creates the final ranking by comparing the measure of the distance from the ideal solution and the farthest distance 

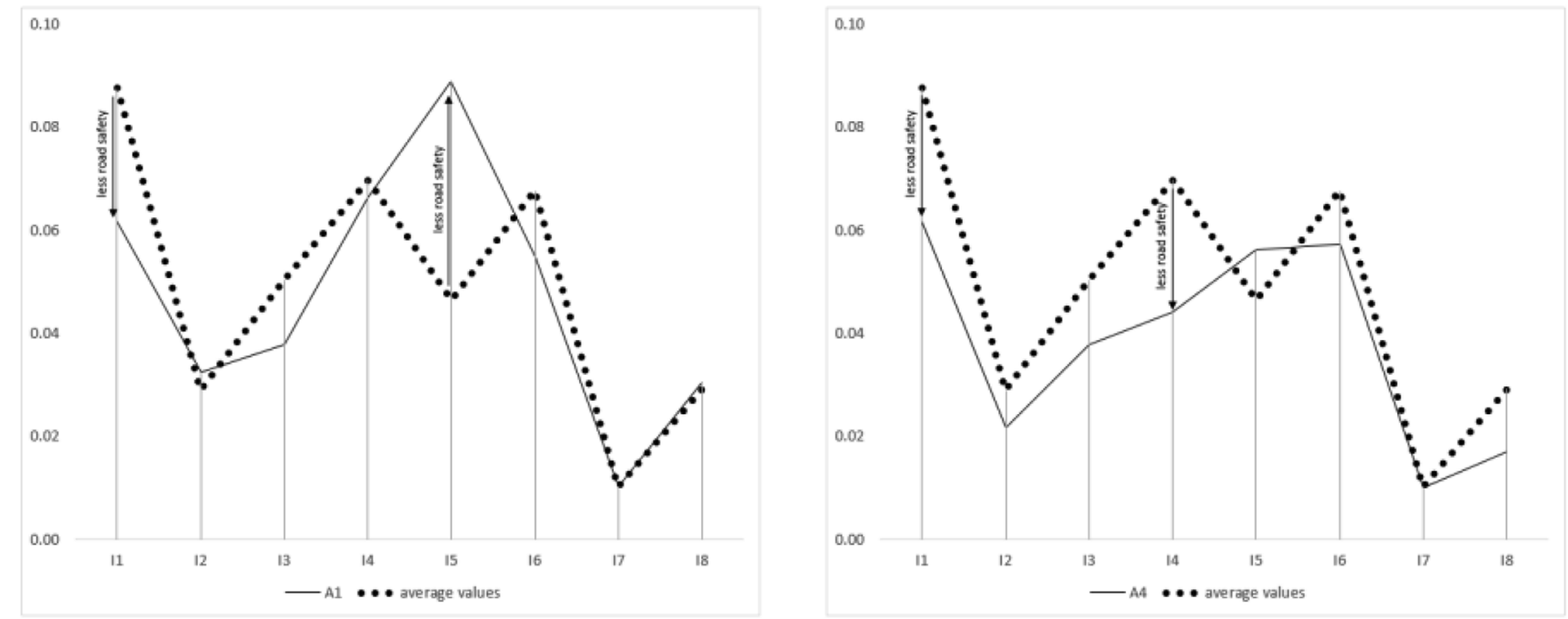

Fig. 2. The distance from the average values.
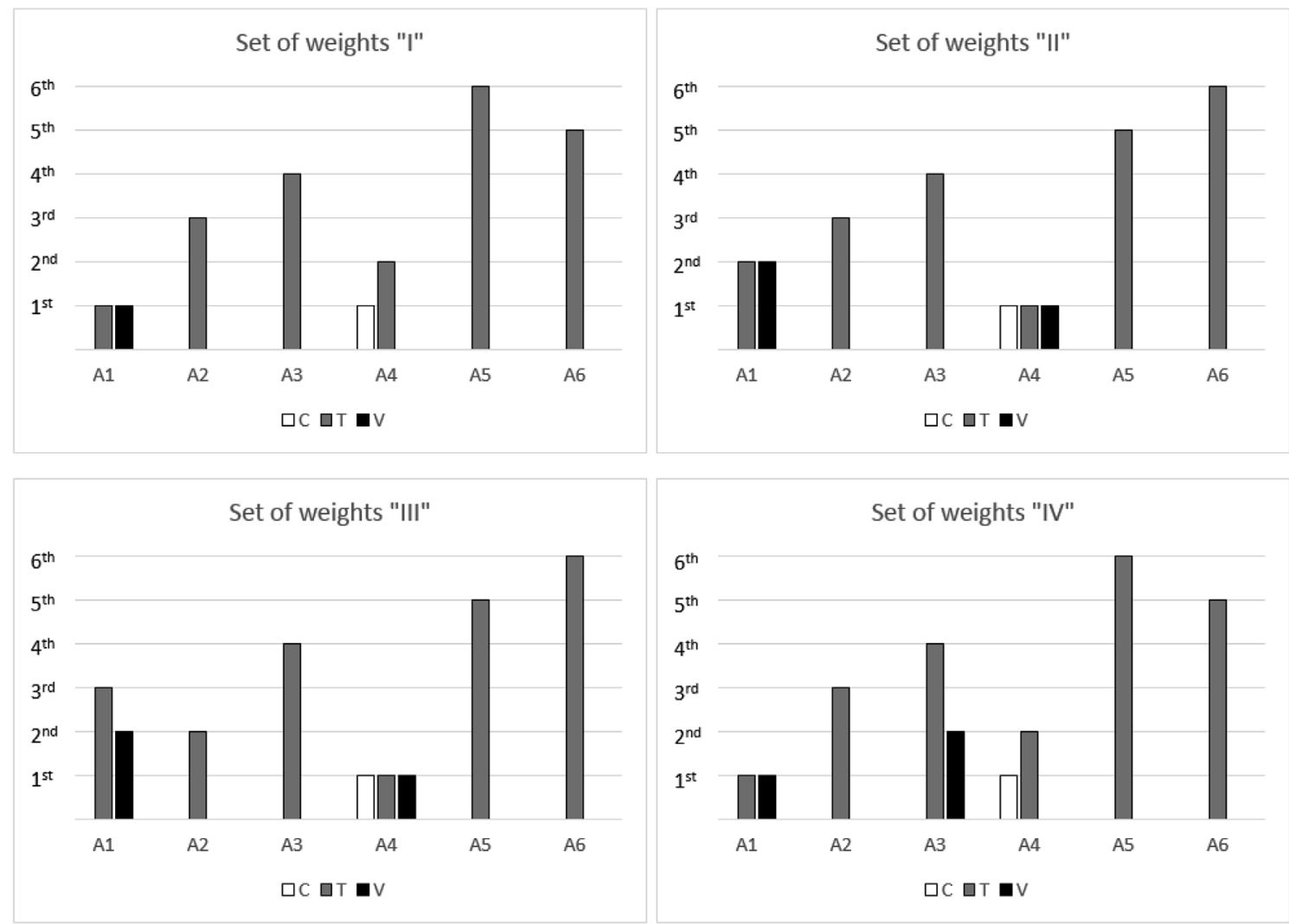

Fig. 3. The best compromise ranking.

Table 8

Set of weights.

\begin{tabular}{llll}
\hline Set of weights & & $\mathrm{D}_{1}$ & $\mathrm{D}_{2}$ \\
\hline I & small range & 0.5 & 0.5 \\
II & & 0.7 & 0.3 \\
0 & DM & 0.6 & 0.4 \\
III & large range & 0.8 & 0.2 \\
IV & & 0.4 & 0.6 \\
\hline
\end{tabular}

from the negative-ideal solution. Table 4 shows the values of closeness of the ideal alternative calculated with the algorithm while the final ranking is given in Table 5 .

The concordance method identifies a single alternative " $\mathrm{A}_{4}$ " with a positive Ic and negative Id. In this case the alternative $\mathrm{A}_{4}$ is identified as the best compromise solution. The indexes provided by the concordance method are shown in Table 6.

The Topsis and Vikor methods yield similar results. In fact, they provide similar hierarchies, which place every intersection in a position that can be never the same, but one place higher or lower with respect to the hierarchy given by the other model. Vikor ranks the intersection 
Table 9

The best compromise ranking.

\begin{tabular}{|c|c|c|c|c|c|c|c|c|c|c|c|c|}
\hline & \multicolumn{12}{|c|}{ Set of weights } \\
\hline & \multicolumn{3}{|l|}{ I } & \multicolumn{3}{|l|}{ II } & \multicolumn{3}{|l|}{ III } & \multicolumn{3}{|l|}{ IV } \\
\hline & C & $\mathbf{T}$ & V & C & $\mathbf{T}$ & V & $\mathrm{C}$ & $\mathbf{T}$ & V & $\mathrm{C}$ & $\mathbf{T}$ & V \\
\hline$A_{1}$ & - & $1^{\text {st }}$ & $1^{\text {st }}$ & - & $2^{\text {nd }}$ & $2^{\text {nd }}$ & - & $3^{\text {rd }}$ & $2^{\text {nd }}$ & - & $1^{\text {st }}$ & $1^{\text {st }}$ \\
\hline $\mathrm{A}_{2}$ & - & $3^{\text {rd }}$ & - & - & $3^{\text {rd }}$ & - & - & $2^{\text {nd }}$ & - & - & $3^{\text {rd }}$ & - \\
\hline $\mathrm{A}_{3}$ & - & $4^{\text {th }}$ & - & - & $4^{\text {th }}$ & - & - & $4^{\text {th }}$ & - & - & $4^{\text {th }}$ & $2^{\text {nd }}$ \\
\hline $\mathrm{A}_{4}$ & $1^{\text {st }}$ & $2^{\text {nd }}$ & - & $1^{\text {st }}$ & $1^{\text {st }}$ & $1^{\text {st }}$ & $1^{\text {st }}$ & $1^{\text {st }}$ & $1^{\mathrm{st}}$ & $1^{\text {st }}$ & $2^{\text {nd }}$ & - \\
\hline$A_{5}$ & - & $6^{\text {th }}$ & - & - & $5^{\text {th }}$ & - & - & $5^{\text {th }}$ & - & & $6^{\text {th }}$ & - \\
\hline$A_{6}$ & - & $5^{\text {th }}$ & - & - & $6^{\text {th }}$ & - & - & $6^{\text {th }}$ & - & - & $5^{\text {th }}$ & - \\
\hline
\end{tabular}

$\mathrm{A}_{4}$ 1st, Topsis 2nd, the intersection $A_{1}$ is ranked 2nd with Vikor, 1st with Topsis. The alternative $A_{3}$ is placed respectively 3rd and 4th with Vikor and Topsis, while the alternative $\mathrm{A}_{2}$ is placed respectively 4 th and $3 \mathrm{rd}$. The concordance analysis identified only the alternative $\mathrm{A}_{4}$ as the best compromise solution and the ranking is not complete. Table 7 and Fig. 3 summarise the rankings obtained with the three methods.

Once the ranking is done, this methodology allows the decision maker to identify the parameters that cause the poor safety performance of the intersections. Fig. 2 shows the weighted normalised values of each criteria (6) for the worst safety intersections in the Topsis ranking (A1 and A4), compared with the average values. For the intersection $A_{1}$, criteria $I_{1}$ and $I_{5}$ have a considerably lower value than the average value. The decision maker can improve road safety at this intersection through actions aimed to improve sight distance and decrease the number of conflict points. In order to improve safety performance of the intersection $\mathrm{A}_{4}$, the decision maker can plan actions aimed to improve sight distance and road surface.

\section{Sensitivity analysis of ranking}

A sensitivity analysis is performed in order to test the robustness of the results obtained taking into account the decision maker preferences. The relative priority of the criteria is varied so as to examine how this changes the best compromise ranking. In order to maintain the significance of the analysis by reducing, to a reasonable limit, the number of the test cases, the criteria are grouped into two homogeneous domains: geometric characteristics $\left(\mathrm{D}_{1}\right)$ and vehicle and pedestrian flow characteristics $\left(D_{2}\right) . I_{1}, I_{2}, I_{3}, I_{4}$ are grouped in the domain $D_{1}$ instead $I_{5}$,
$I_{6}, I_{7}, I_{8}$ in $D_{2}$. An equal weight is assigned to all criteria grouped in the same domain. The sensitivity analysis is based on the fixed schemes of weights (Giuliano, 1985) and considers the case where the decision maker makes mistakes in his judgment. With the fixed schemes of weights the authors consider two different range of weights, small and large range, with respect to the weights given by the decision maker. The Decision maker preference is expressed by the following vector:

$w=\left(w_{D 1}, w_{D 2}\right)=(0.6,0.4)$

In the sensitivity analysis 4 different schemes of weights are considered. In the set "I" the authors consider a small decrease in weight of parameters related to geometric characteristics $\left(w_{D 1}\right.$, from 0.6 points to 0.5 ) and a small increase in weight of parameters related to traffic flow $\left(w_{\mathrm{D} 2}\right.$, from 0.4 to 0.5$)$. In the set "II" the weight of $\mathrm{w}_{\mathrm{D} 1}$ increases from 0.6 to 0.7 and the weight of $\mathrm{w}_{\mathrm{D} 2}$ decreases from 0.4 to 0.3 . In the set "III" the weight of $\mathrm{w}_{\mathrm{D} 1}$ increases from 0.6 to 0.8 and the weight of $\mathrm{w}_{\mathrm{D} 2}$ decreases from 0.4 to 0.2 ). In the set "IV" the weight of $\mathrm{w}_{\mathrm{D} 1}$ decreases from 0.6 to 0.4 and the weight of $\mathrm{w}_{\mathrm{D} 2}$ increases from 0.4 to 0.6 .

$\left(w_{\mathrm{D} 1}\right)_{I}=\left(w_{D 1}\right)_{0}-0.1$

$\left(w_{\mathrm{D} 1}\right)_{I I}=\left(w_{\mathrm{D} 1}\right)_{0}-0.1$

$\left(w_{\mathrm{D} 1}\right)_{I I I}=\left(w_{\mathrm{D} 1}\right)_{0}+0.2$

$\left(w_{\mathrm{D} 1}\right)_{\mathrm{IV}}=\left(w_{\mathrm{D} 1}\right)_{0}-0.2$

$\left(w_{\mathrm{D} 2}\right)_{n}=1-\left(w_{\mathrm{D} 1}\right)_{n}$

The schemes of weights are show in the following table (Table 8).

Table 9 shows for each method considered, Concordance Analysis "C", Topsis "T" and Vikor dquo;V", the best compromise ranking. In the set number I and IV, the domain related to geometric characteristics $\left(D_{1}\right)$, takes a lower weight than the Decision Maker preferences "set 0". Road intersection " $\mathrm{A}_{1}$ " proves to be the road intersection with the worst safety condition as according to both Topsis and Vikor methods. In the Concordance Analysis, no alternative has a positive concordance index and a negative discordance index and a compromise ranking is not identified according the algorithm. If higher weight is considered for $\mathrm{D}_{1}$ (set number II and III), the first choice of the two methods moves away from the $A_{1}$ and the intersection with the worst safety condition is the $A_{4}$. The final ranking of Topsis considers $A_{2}$ e $A_{3}$ as the most unsafe after $A_{1}$ e $A_{4}$ while $A_{5}$ and $A_{6}$ remain in the last place of the ranking, as road intersections with the best safety conditions.

The sensitivity analysis confirms conclusions based on the decision

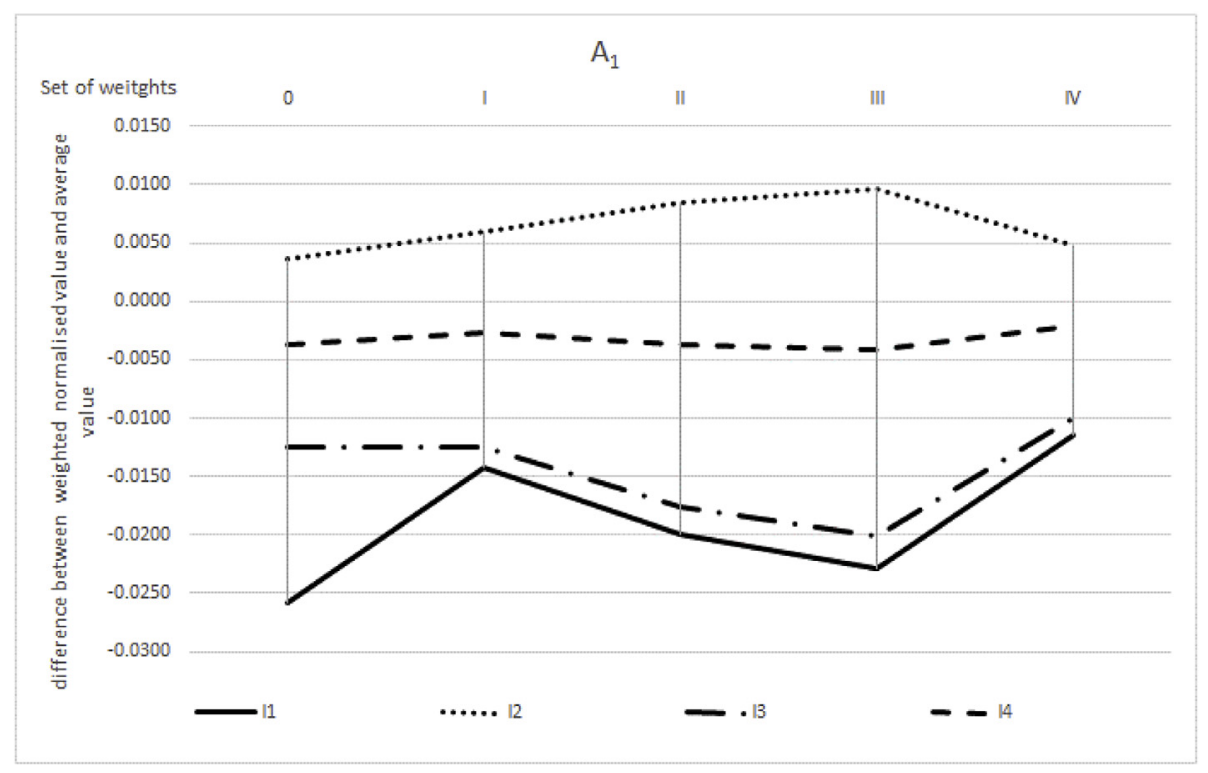

Fig. 4. The influence of criteria I1, I2, I3, I4 for the alternative $A_{1}$. 


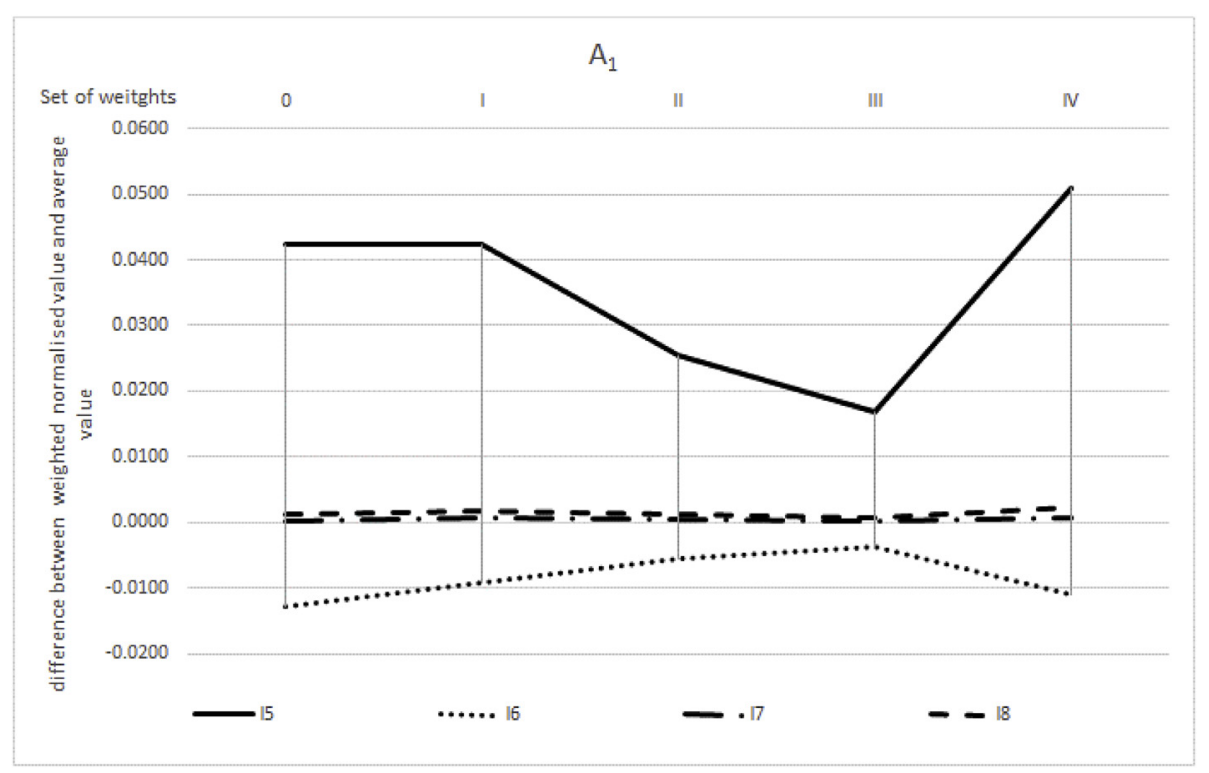

Fig. 5. The influence of criteria I5, I6, I7, I8 for the alternative $A_{1}$.

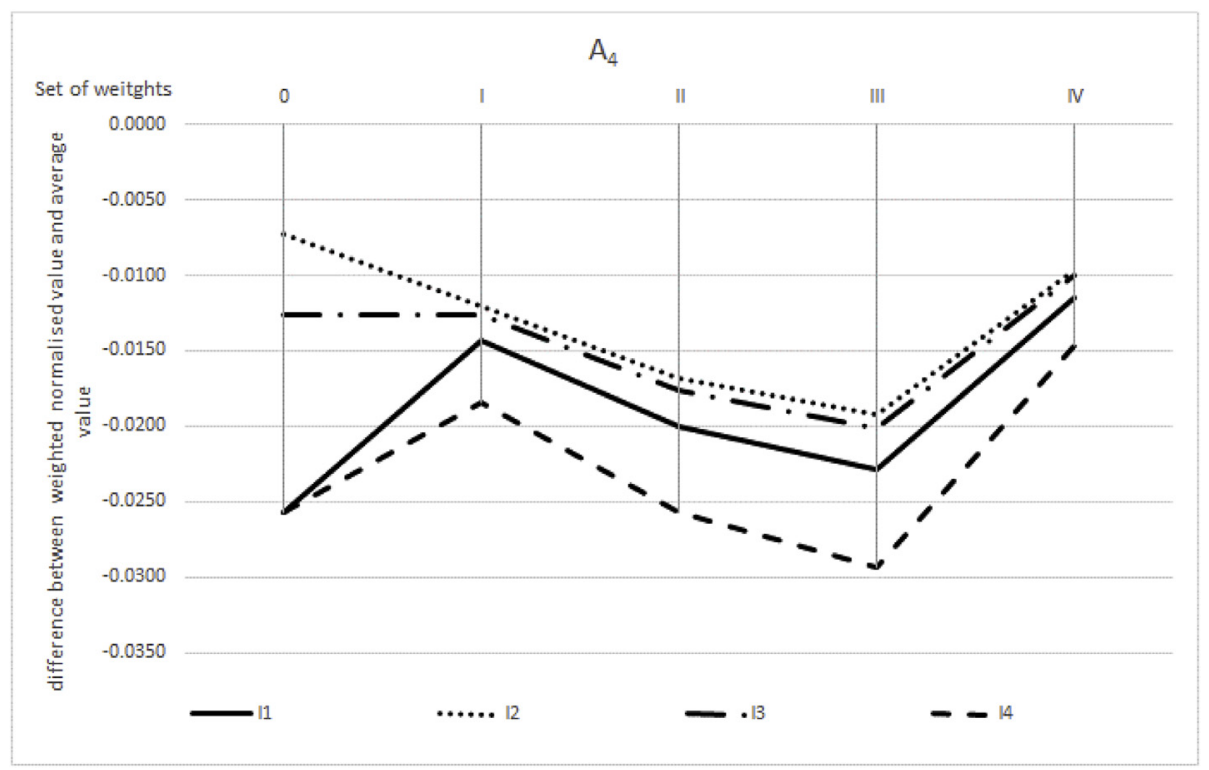

Fig. 6. The influence of criteria I1, I2, I3, I4 for the alternative $\mathrm{A}_{4}$.

maker preferences. Figs. 4-7 show the difference between weighted normalised value (for the intersections in the first places in the intersections ranking $\mathrm{A}_{1}$ and $\mathrm{A}_{4}$ ) and average value considering all the intersections of the decision set. Only small variations are derived by applying the different set of weights and no substantial changes are observed with respect to the influence of each criterion in determining the ranking.

\section{Conclusions}

In this paper a methodology is defined with the aim to support city managers in setting road safety priority interventions in case of limited financial resources. A decision support system based on multicriteria methods is proposed in order to build a hierarchy of road intersections according to a set of evaluation criteria. The methodology proposed allows the city manager, as Decision Maker, to plan intervention priority, according to hierarchy based on safety conditions. In this work the authors have overcome the important aspects regarding the choice of multi-criteria methods at the base of a Decision Support System, already addressed in previous works. The Concordance Analysis does not always allow Decision Maker to identify the best compromise solution (Fancello et al., 2015) while Electre III method outperforms Concordance Analysis for its ability to consider different degree of preference but in practice it is very difficult, for a decision maker to assign a numerical value to the thresholds (Fancello et al., 2014). In this paper the usefulness and results of the Concordance Analysis is compared with the methods Vikor and Topsis. The methods able to solve hierarchy issues of a set of road elements, presented in the scientific literature, use linear regression analysis based on the number of accidents. A decision support system based on multi-criteria methods is suitable in case of assessment based on different parameters related to road safety instead of the number of accident (in fact, accident data maybe not available for the whole network or not described in a suitable way). In this paper, the three multi-criteria methods, Topsis, Vikor and Concordance Analysis are applied to a real case study in order to build a hierarchy of six road intersection of Villacidro city, in Italy. The 


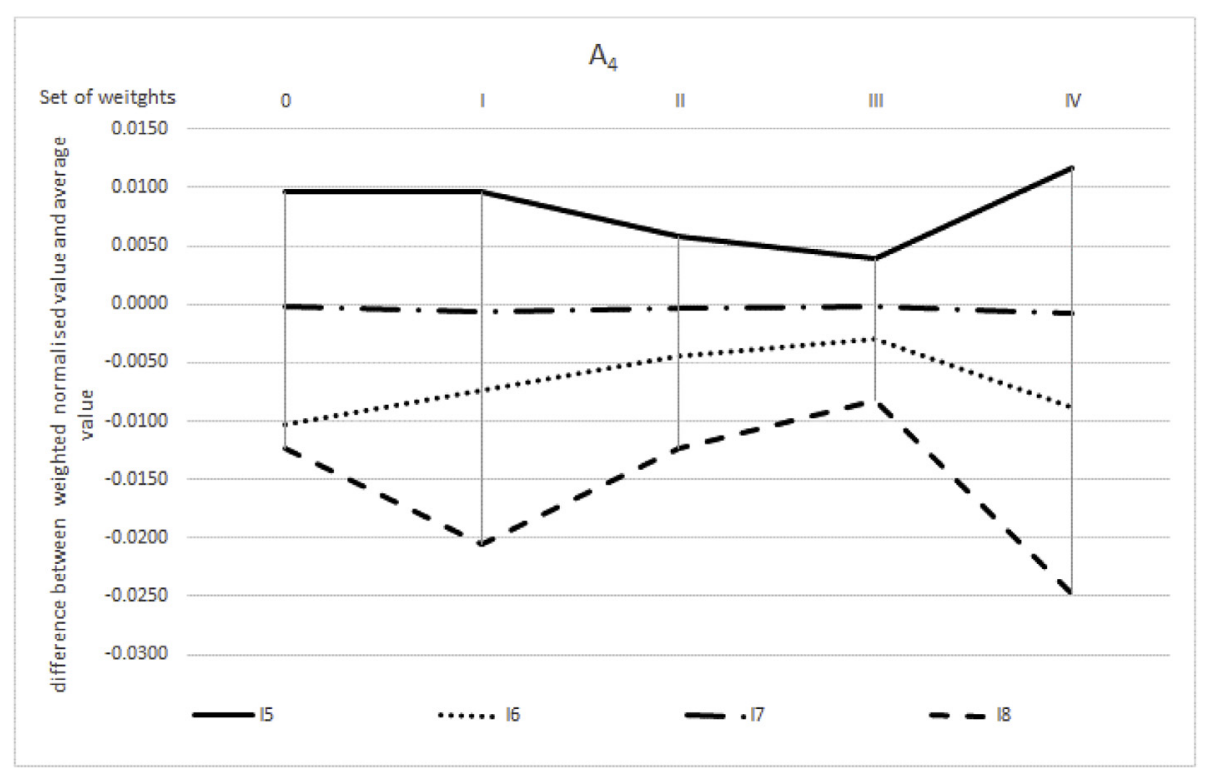

Fig. 7. The influence of criteria I5, I6, I7, I8 for the alternative $\mathrm{A}_{4}$.

Vikor and Topsis methods have given similar results and place the first four intersections $\left(A_{1}, A_{2}, A_{3}, A_{4}\right)$ in a position that can be never the same, but one place higher or lower with respect to the hierarchy provided by the other model.

As result of the analysis, the Topsis method has proved to be the most suitable method to provide support to a Decision Maker. The Topsis has given a complete ranking of alternative by comparing the measure of the distance of each alternative from the positive ideal solution and the farthest distance from the negative-ideal solution, overcoming some negative aspects related to other methods.

A sensitivity analysis has been performed. In the sensitivity analysis, the scheme of weights assigned by the decision maker is changed in order to examine the impact on the results. The sensitivity analysis has confirmed similar results between Topsis and Vikor method and the usefulness of Topsis compared to the Concordance Analysis and Vikor.

\section{References}

Agarwal, P.K., Patil, P.K., Mehar, R., 2013. A methodology for ranking road safety hazardous locations using analytical hierarchy process. Procedia Soc. Behav. Sci. 104, 1030-1037.

Bao, Q., Ruan, D., Shen, Y., Hermans, E., Janssens, D., 2012. Improved hierarchical fuzzy TOPSIS for road safety performance evaluation. Knowl. Base Syst. 32, 84-90.

Belton, V., Stewart, T., 2002. Multiple Criteria Decision Analysis: an Integrated Approach. Springer Science \& Business Media.

Chen, S.J.J., Hwang, C.L., Beckmann, M.J., Krelle, W., 1992. Fuzzy Multiple Attribute Decision Making: Methods and Applications. Springer-Verlag, New York, Inc.

Colonna, P., 2002, July, July. Proposal for a safety function for evaluating the road efficiency level. In: The Third International Conference on Traffic and Transportation, Guilin-cina.

Deng, H., Yeh, C.H., Willis, R.J., 2000. Inter-company comparison using modified TOPSIS with objective weights. Comput. Oper. Res. 27 (10), 963-973.

Fancello, G., Soddu, S., Fadda, P., 2017. An accident prediction model for urban road networks. J. Transport. Saf. Secur. 1-19 ISO 690.

Fancello, G., Carta, M., Fadda, P., 2015. A decision support system for road safety analysis. Transport. Res. Procedia 5, 201-210.

Fancello, G., Carta, M., Fadda, P., 2014. A decision support system based on Electre III for safety analysis in a suburban road network. Transport. Res. Procedia 3, 175-184.

Figueira, J., Greco, S., Ehrgott, M. (Eds.), 2005. Multiple Criteria Decision Analysis: State of the Art Surveys, vol 78 Springer Science \& Business Media.

Gardziejczyk, W., Zabicki, P., 2014. The influence of the scenario and assessment method on the choice of road alignment variants. Transport Pol. 36, 294-305.

Giuliano, G., 1985. A multicriteria method for transportation investment planning. Transport. Res. Gen. 19 (1), 29-41.

Hermans, E., Van den Bossche, F., Wets, G., 2008. Combining road safety information in a performance index. Accid. Anal. Prev. 40 (4), 1337-1344.

Huang, H., Abdel-Aty, M., 2010. Multilevel data and Bayesian analysis in traffic safety. Accid. Anal. Prev. 42 (6), 1556-1565.

Hwang, C.L., Yoon, K., 1981. Multiple attribute decision making. In: Lecture Notes in Economics and Mathematical Systems, vol 186 Springer-Verlag, Berlin.

Jahan, A., Edwards, K.L., 2013. VIKOR method for material selection problems with interval numbers and target-based criteria. Mater. Des. 47, 759-765.

Janssen, S.T.M.C., 1991, January. Indicators for traffic safety: a new yardstick for safety. In: Proceedings of the Second International Conference on New Ways for Improved Road Safety and Quality of Life, pp. 117-126 Tel-Aviv, Israel, October 7-10, 1991.

Kang, D., Park, Y., 2014. Review-based measurement of customer satisfaction in mobile service: sentiment analysis and VIKOR approach. Expert Syst. Appl. 41 (4), 1041-1050.

Keymanesh, M., Ziari, H., Roudini, S., Nasrollahtabar Ahangar, A., 2017. Identification and prioritization of "black spots" without using accident information. Model. Simulat. Eng. 2017.

Manual, H.C., 2000. Highway Capacity Manual. (Washington, DC).

Miranda-Moreno, L., Fu, L., Saccomanno, F., Labbe, A., 2005. Alternative risk models for ranking locations for safety improvement. Transport. Res. Rec.: J. Transport. Res. Board 1908, 1-8.

Moghassem, A.R., 2013. Comparison among two analytical methods of multi-criteria decision making for appropriate spinning condition selection. World Appl. Sci. J. 21 (5), 784-794.

Mohanty, P.P., Mahapatra, S.S., 2014. A compromise solution by VIKOR method for ergonomically designed product with optimal set of design characteristics. Procedia Mater. Sci. 6, 633-640.

Olteanu, A.L., Bisdorff, R., Meyer, P., 2011. A contribution to the multiple criteria preordering problematique. In: 74th Meeting of the European Working Group Multiple Criteria Decision Aiding. Yverdon-Les-Bains, Switzerland 06-08 october 2011.

Opricovic, S., 1998. Multicriteria optimization of civil engineering systems. Facul. Civ. Eng. Belgrade 2 (1), 5-21.

Sarrazin, R., De Smet, Y., 2011, December. A preliminary study about the application of multicriteria decision aid to the evaluation of the road projects' performance on sustainable safety. In: Industrial Engineering and Engineering Management (IEEM), 2011 IEEE International Conference on. IEEE, pp. 727-732.

Wu, H.Y., Lin, Y.K., Chang, C.H., 2011. Performance evaluation of extension education centers in universities based on the balanced scorecard. Eval. Progr. Plann. 34 (1), 37-50.

Yoon, K.P., Hwang, C.L., 1995. In: Multiple Attribute Decision Making: an Introduction, vol 104 Sage Publications.

Zopounidis, C., Doumpos, M., 2002. Multicriteria classification and sorting methods: a literature review. Eur. J. Oper. Res. 138 (2), 229-246. 